\title{
T-COLORINGS, DIVISIBILITY AND THE CIRCULAR CHROMATIC NUMBER
}

\author{
ROBERT JANCZEWSKI \\ Department of Algorithms and Systems Modelling \\ Gdańsk University of Technology \\ Narutowicza 11/12, Gdańsk, Poland \\ e-mail: skalar@eti.pg.gda.pl \\ Anna Maria Trzaskowska \\ Department of Applied Informatics in Management \\ Gdansk University of Technology \\ Narutowicza 11/12, Gdańsk, Poland \\ e-mail: anna.trzaskowska@pg.edu.pl \\ AND \\ KRZYSZTOF TUROWSKI \\ Center for Science of Information \\ Purdue University West Lafayette, Indiana, USA \\ e-mail: krzysztof.szymon.turowski@gmail.com
}

\begin{abstract}
Let $T$ be a $T$-set, i.e., a finite set of nonnegative integers satisfying $0 \in T$, and $G$ be a graph. In the paper we study relations between the $T$-edge spans $\operatorname{esp}_{T}(G)$ and $\operatorname{esp}_{d \odot T}(G)$, where $d$ is a positive integer and

$$
d \odot T=\{0 \leq t \leq d(\max T+1): d \mid t \Rightarrow t / d \in T\} .
$$

We show that $\operatorname{esp}_{d \odot T}(G)=d \operatorname{esp}_{T}(G)-r$, where $r, 0 \leq r \leq d-1$, is an integer that depends on $T$ and $G$. Next we focus on the case $T=\{0\}$ and show that

$$
\operatorname{esp}_{d \odot\{0\}}(G)=\left\lceil d\left(\chi_{c}(G)-1\right)\right\rceil,
$$

where $\chi_{c}(G)$ is the circular chromatic number of $G$. This result allows us to formulate several interesting conclusions that include a new formula for the
\end{abstract} circular chromatic number

$$
\chi_{c}(G)=1+\inf \left\{\operatorname{esp}_{d \odot\{0\}}(G) / d: d \geq 1\right\}
$$


and a proof that the formula for the $T$-edge span of powers of cycles, stated as conjecture in [Y. Zhao, W. He and R. Cao, The edge span of T-coloring on graph $C_{n}^{d}$, Appl. Math. Lett. 19 (2006) 647-651], is true.

Keywords: $T$-coloring, circular chromatic number.

2010 Mathematics Subject Classification: 05C15.

\section{REFERENCES}

[1] M.B. Cozzens and F.S. Roberts, T-colorings of graphs and the channel assigment problem, Congr. Numer. 35 (1982) 191-208.

[2] K. Giaro, R. Janczewski and M. Małafiejski, A polynomial algorithm for finding Tspan of generalized cacti, Discrete Appl. Math. 129 (2003) 371-382. doi:10.1016/S0166-218X(02)00575-9

[3] K. Giaro, R. Janczewski and M. Małafiejski, The complexity of the T-coloring problem for graphs with small degree, Discrete Appl. Math. 129 (2003) 361-369. doi:10.1016/S0166-218X(02)00576-0

[4] G. Fan, Circular chromatic number and Mycielski graphs, Combinatorica 24 (2004) 127-135. doi:10.1007/s00493-004-0008-9

[5] W.K. Hale, Frequency assigment: theory and applications, Proc. IEEE 68 (1980) $1497-1514$. doi:10.1109/PROC.1980.11899

[6] R. Janczewski, Divisibility and T-span of graphs, Discrete Math. 234 (2001) 171-179. doi:10.1016/S0012-365X(00)00378-2

[7] R. Janczewski, Greedy T-colorings of graphs, Discrete Math. 309 (2009) 1685-1690. doi:10.1016/j.disc.2008.01.049

[8] J.S.-T. Juan, I. Sun and P.-X. Wu, T-coloring on folded hypercubes, Taiwanese J. Math. 13 (2009) 1331-1341. doi:10.11650/twjm/1500405511

[9] A. Raychaudhuri, Further results on T-coloring and frequency assignment problems, SIAM J. Discrete Math. 7 (1994) 605-613. doi:10.1137/S0895480189171746

[10] D. Moser, The star-chromatic number of planar graphs, J. Graph Theory 24 (1997) $33-43$. doi:10.1002/(SICI)1097-0118(199701)24:1〈33::AID-JGT5〉3.0.CO;2-K

[11] B. Tesman, Applications of forbidden difference graphs to T-coloring, Congr. Numer. 74 (1990) 15-24.

[12] A. Vince, Star chromatic number, J. Graph Theory 12 (1988) 551-559. doi:10.1002/jgt.3190120411 
[13] Y. Zhao, W. He and R. Cao, The edge span of T-coloring on graph $C_{n}^{d}$, Appl. Math. Lett. 19 (2006) 647-651.

doi:10.1016/j.aml.2005.08.016

[14] X. Zhu, Circular chromatic number: a survey, Discrete Math. 229 (2001) 371-410. doi:10.1016/S0012-365X(00)00217-X

[15] X. Zhu, Recent developments in circular colouring of graphs, Algorithms Combin. 26 (2006) 497-550.

doi:10.1007/3-540-33700-8_25

Received 19 March 2018

Revised 16 October 2018

Accepted 7 December 2018 